\title{
A Brief Analysis on the Study of Silk Road Non-Chinese Literature
}

\author{
Ge Zhang \\ School of Humanities, Xinjiang University, Urumqi 830046, China
}

Keywords: Silk Road; Literature; Study.

\begin{abstract}
Silk Road non-Chinese literature is the original records for history, culture and national changes. It is an incomparable and significant part of literature study. Starting with the research of non-Chinese documents in the eastern section of Silk Road, this article focuses on the research value of non-Chinese literatures on Silk Road, aiming to awaken the academic community to pay attention to its multi-level research.
\end{abstract}

\section{Introduction}

The Silk Road is the land from Central Plains in the east, to the coast of the Mediterranean Sea in the west, across the Eurasian continent, stretching over 7000 kilometers. With the Central Asia Silk Road as its boundary, the eastward stretch to Xi'an is called the eastern Silk Road, which traverses the entire Western Regions. On the east line of the Silk Road, there lived Daxia, Anxi, Seychelles, Yue Shi, Sogdia, Tochallan, Huns, Rouran, Tuoba, Turks, Hui, Tubo, Xixia, Mongolia, India, Han etc.. There are 19 languages spoken by them. Among them, Mani, Sogdian, Uighur, such as Nepal, Syria, Arab, Tibet, Brahmi, Lu, Chinese, etc. are the most widely used languages. Since these kinds of documents, especially non-Chinese documents, are the original records of local tribes concerning the history, geography, economy, culture, nationality, literature, art, production, social life, war and foreign relations along the Silk Road, they are not artificially destroyed, so it has valuable research value.

\section{Foreign Research on Non - Chinese Documents on Silk Road}

Western studies of non-Chinese literatures in the eastern section of Silk Road mainly originated from the investigation and exploration of silk roads by Western adventurers since the 19th century. It is undeniable that this scientific investigation is carried out under the background that the West has increasingly colonized the Orient. Therefore, the Great Nation chauvinism and the "Western Civilization of the East" run through in accordance with the progress of the study and the different perspectives. It can be divided into four stages:

\subsection{Late 19th Century to Early 20th Century}

The main research during this period was a general introduction of the exploration experience and the collection of the eastern Silk Road. Such as Henri Yul's Eastern Regional Records Series (London, 1866), Sven Heding's Heart of Asia (Leipzig, 1903), Hermann's Silk Road between Ancient China and Syria (Berlin, 1910), Li Sidofen's five volumes, "The Travel Notes of China" (Berlin, 1877-1912), Huntington's "The Pulse of Asia" (New York, 1907), James's " The Golden Journey of Markham "(London, 1913), Stein's Western Archean Pictures (Oxford, 1921) and Glendower's Archaeological Work Report (Munich, 1906), China Xinjiang's ancient Buddhist temples "(Berlin, 1912), Ono's mystical" Buddhist art of Gandhara "(Tokyo, 1923). In addition, direct research on Silk Road literature has begun to emerge. Such as "a Manichaeus contract found in China" by Chawhans (Paris, 1913), Hartmann's "Turkic instrument unearthed by Erken (Berlin, 1905)," Ye Wenzhu "(Kolkata, 1893-1912)," Fragments of Buddhist Documents Discovered in Xinjiang "(Oxford, 1916).

\subsection{S-1940S}

In the previous period, a large number of historical relics in the eastern section of the Silk Road were looted by Western explorers or oriental scholars. Therefore, the research object of this period was mainly the ancient national language in the eastern section of Silk Road. The description and 
interpretation of the literature. Such as Brecque's "Middle Turkic vocabulary" (Budapest, 1928), Bailey's Khotan Documents (Copenhagen, 1938), Khotan Documents (I-VI Cambridge, 1945-1967) Dreyfus's "Back Language" (Leningrad, 1928), Kono's "The Hotan and the Seychelles Grammar" (Leipzig, 1941), Boyce's Stanford Instruments Found in Xinjiang (Oxford, 1927), Thomas's "Tibetan Literature on Xinjiang, China" (London, 1935). Of course, compared with the previous stage, Silk Road archeology research and political, economic, cultural, religious and other research became more prosperous. Such as Lecock's "Central Asia Buddhism" (Berlin, 1922-1933), Rama's Nestorianism (Tubingen-Leipzig, 1930), Henning's Central Asian Manichaeism (Oxford, 1934), The "Islamic culture" of Bartowad (Kolkata, 1934), Sven Hedin's Silk Road (Leipzig, 1936), Bergman's Xinjiang Archeology (Stockholm, 1939) and so on.

\section{$2.31950 \mathrm{~s}-1980 \mathrm{~s}$}

The further study of the ancient languages of the Silk Road and the study and classification of various languages and documents have become the core contents of this phase. Such as Feng Jiban's Old Turkic Grammar (Bonn, 1950), Emmy's Guide to Yu's Literature (Tokyo, 1979), Studies in Yuanyu (Vienna, 1982) Back to Back Dictionary: Early Islamic Central Asian Turkic Documents (Wiesbaden, 1977), Bailey's Yuzissen Dictionary (Cambridge, 1979), Clarke's Introduction to Xinjiang Uyghur World Customs Documents (Blum Dayton, 1975), Beuys' Manitian Eylan instruments in the Turpan-Tibetan Turks (Berlin, 1960), Zondman's Mani-Sogdian instruments (Berlin, 1985) Special "German Oriental literature" and so on. On the basis of these literary studies, the history of the Silk Road, ethnic, cultural, religious, artistic and geographical studies are also booming and shining. Such as the Silk Road by Bernius (Paris, 1963), the History of Central Asia and the Silk Road during Islam (Amsterdam, 1983) by Hau Senge, and Yang Peter's Xinjiang-Silk Road: Introduction of Islam into China (New York, 1987), Huayanei's "Natural Changes in the Ancient Silk Road" (Tokyo, 1977), "The World of the Silk Road" by Tsubovsky (Tokyo, 1981), Nagasawa History and Culture of the Silk Road (Tokyo, 1983) by Haruki and Hamata's Collection of Central Asian Historical Records of Pre-Islamic Times (Budapest, 1979), Asimson's Manichaeism Studies Perhhaugen, 1965), The Study of Christianity in Central and Far East by Pope Berthe (Paris, 1973), Sotheby's The Twofold Directory of Literature (Wiesbaden, 1959) and others.

\subsection{0s - Early 21st Century}

Using the research results of ancient Chinese Study in the eastern section of the Silk Road, the study on the history, culture, religion, art, commerce and trade of the Silk Road has become a new bright point in the study of the Silk Road in the 21 st century. Such as Richard's "Religion on the Silk Road" (London, 1999), Wu Fangsi's Silk Road 2000 (London, 2000), Massey's Silk Road: Cultural and Trade Freeway (New York, 2000), Susan's Silk Road Life (London, 1999), Richard's Religion on the Silk Road (London, 1999), Longan's Thousand-Buddha Caves: Chinese Art on the Silk Road, (London, 1990), John's Proceedings of the Silk Road Antiquities and Cultures (Kamakura, 1997), Dunhuang and Turpan in Central Asia: Contents and Protection of Ancient Writings in Central Asia, Annabel's Ore Ernst \& Young "Silk Road" (Paris, 1992), Pino's "Tolhu writers and Buddhist literature in the Western Regions" (Paris, 1991) Von Herbert's "Nomadic and Settlers in the Western Regions" (Paris, 1990), and co-authored "Silk and Happy Life" (Rome, 1992), "The Western Regions, the Land of the Buddha, the Catalog of the Grand Palais" (Paris, 1995) Wait.

Although western scholars have made fruitful achievements in the study of non-Chinese literatures on Silk Road, literature classification is not so scientific, literature review and research value mining is not deep enough, different kinds of literature on the survey is not comprehensive.

\section{Research on Non - Chinese Documents on Silk Road in Chinese}

The study of non-Chinese literary works in the eastern section of Silk Road started in Ming Dynasty. The representative book is HuaYi Translation (Beijing, 1379), which includes the articles entitled "Commentary from Gaochang Hall", " Text ". The late research is divided into three stages: 


\subsection{From the Early Twentieth Century to the Seventies.}

The initial research in this period mainly focused on the translation of foreign-language achievements, but later added a proof of foreign language. Such as: Bo Xi He, Wang Guowei translation of "the recent Oriental language and ancient history of the invention and its conclusions" (Beijing, 1924), Bosh and Feng Chengjun translated "Tocharian test" (Beijing, 1957 (Shanghai, 1935), Marco Polo and Zhang Xingliang's "Travels to Marco Polo" (Shanghai, 1936), Clavíjo, and "A Study of the Western Regions" by Yang Zhao- An introduction to the history of the Western Regions Civilization (Shanghai, 1944), An Introduction to the Western Regions Travels by Anonymous (Beijing, 1941), Haneda Akio, and Zheng Yuanfang (1944) Wait. In addition, studies on language, culture and history along the Silk Road since the founding of the People's Republic of China, especially in Xinjiang, have gradually surfaced. Although these studies mainly rely on the Chinese literature and ethnic minorities, modern literature, but still have some reference value. Such as Uyghur rhetoric common sense (Urumqi, 1979), Diyidi "Uyghur folk proverbs and riddles" (Beijing, 1957), and the text reform commission's "Kazakh concise method" (Urumqi, 1954) ), Ktappba's "History of Mankind and Kazakhs" (Urumqi, 1948-1949), etc.

\subsection{0s-Early 21st Century}

The characteristic of this period of study is that Chinese scholars began to independently study the non-Chinese languages and their documents in the eastern section of Silk Road. Such as the "Ancient Scroll of the Sand Sea in Shamian Village - Lu Lü Shu" unearthed in China (Beijing, 1988), the study on spit fire in Ji Xianlin (Nanchang, 1998), Hu Zhenhua and Huang Runhua (Urumqi, 1981), "Gaochang Museum Accent" (Beijing, 1984), "Study of ancient Chinese characters" by the Research Society for Ancient Chinese Characters. In addition to the research on the ancient writing, the study of language and writings of the Silk Road's modern nation also splendidly. For example, Liu Yitang's Uyghur Studies (Taipei 1987), Geng Shimin's Modern Kazakh Grammar (Beijing 1989) and Cheng Chih-Liang's Uzbek Janes (Beijing 1987). At the same time, with the aid of the Chinese literature and the existing research achievements abroad, the special studies on the history, geography, culture, art, religion and archeology of the Silk Road are also flourishing and fruitful. Such as Guo Sifen's "Trinidad Silk Road" (Taipei, 1981), Wu Bolun's Silk Roads of Friendship and Communication (Xian, 1983), Yang Jianxin's Silk Road (Lanzhou, 1988), Chen Liang's Silk Road (Shanghai, 1981), Geng Shimin's Introduction to Ancient Uighur Culture and Literature (Urumqi, 1983) and Shen Fuwei's History of Chinese and Western Cultural Exchanges (Lanzhou, 1983), the Silk Road and the Western Regions Culture and Art (Shanghai, 1985), Zhou Jingbao's Musical Culture of the Silk Road (Urumqi, 1987), the Silk Road Modeling Art of Xinjiang Art Editing Department (Urumqi, 1985) and the Silk Road Man (Beijing, 1981), Zhang Zhiyao's Prairie Silk Road and Civilization in Central Asia (Urumqi, 1994).

\subsection{The First Decade of the 21st Century.}

Based on the theory of language and literature, the combination of language and history is a new trend in the study of non-Chinese literatures in the eastern part of Silk Road in the 21 st century. For example, Liu Wen-shu's Manuscripts on the History of the Shathai (Beijing, 2007), Huang Shengzhang's Collection of Ancient Western Articles (Hefei, 2010), Yu Tai-shan's Early Silk Road Literature Research (Beijing 2005) Yongming's Historical Records of the Western Regions in Ancient Turks Literature (Xi'an, 2014), Geng Shimin's Introduction to History and Culture in Xinjiang (Beijing, 2006), A Collection of Xinjiang Literature and History (Beijing, 2001), Research on Ancient Uyghur Literature Beijing, 2003), Introduction of Uyghur Ancient Writings and Ancient Documents by Niu Ruji (Urumqi, 2000), Oasis of Culture (Urumqi, 2005), and Altai Civilization and Humanitarian Western Regions (Urumqi, 2003). Since the Huiwen literature is the most important non-Chinese literature in the eastern section of the Silk Road, studying its language is the main direction of development of Chinese scholars in recent ten years. Such as The Reciprocal Literary and Economic Documents by Lan Jingwei (Lanzhou, 2012), Deng Hao and Yang Fuxue (Lanzhou, 2002), Geng Shimin's Research on the Social and Economic Documents of Huiwen (Beijing, 2006); Li Zengxiang's "Brief Papers on the Language of Back Papers" (Urumqi, 2000); "Foundation of Turks 
Linguistics" (Beijing, 2013); Zhang Tieshan's Studies on Language Structures of Back Papers (Beijing, 2004) Introduction to Turkic Linguistics by Yi Mu (Beijing, 2004), The Ancient Uyghur Literature Tutorial (Beijing, 2006).

It can be said that in recent years, our study on non-Chinese literatures in the eastern section of Silk Road has the potential to catch up later. Flaws do not cover up; some research limits are also increasingly prominent. For example, the combination of linguistics and textual research theory is not close enough, the degree of integration of history and linguistics is not deep enough, the translation and justification of related research are not comprehensive enough, and so on. At the same time, because it is impossible to directly read most non-Chinese literatures, just rely on the western research results, coupled with the lack of foreign language ability, it is impossible to make a correct assessment of foreign studies, and may even be repeated by mistake.

\section{The Research Value of Silk Road Non - Chinese Literature}

\subsection{Enrich the History and Culture of the Silk Road, Enhance the Cohesion Among All Ethnic} Groups in Xinjiang, and Deepen Their Recognition of the Chinese Nation and Culture.

The creator of the Silk Road history and culture is the people of all ethnic groups living in this land. At the same time, the eastern section of the Silk Road has been a stage where different ethnic groups live together. Although ethnic minority local governments in the eastern section of the Silk Road also met with the Central Plains dynasties, they mostly interacted with each other and lived together to create the Chinese culture. Taking the 5-7th century Gaochang country as an example, local men's costumes are Western style and women's style is Mainland; Chinese characters are used in the texts, but Western characters are also used in the texts, or in the Western texts when they are studying classical Chinese documents and many more. All of this can be seen as a product of the integration of different cultures. This cultural integration has played a certain role in promoting the formation of the Chinese nation's culture.

\subsection{To form a Correct View of Nation and History, to Refute the Pretexts and Heresies of}

Anti-China Forces and National Separatists in the West and to Safeguard the Unification of the Motherland and Social Stability.

The concept of nation is one of the views and opinions of people on the national and ethnic issues. The concept of history, also known as "the view of social history," is a fundamental view of people's social history, the general view, but also an integral part of the world outlook. Because of the differences in the political systems between China and the West, for a long time Western anti-China forces have always racked their brains in an attempt to carry out the so-called "peaceful evolution." One of its main tactics is to distort the concept of history and the concept of nation in an attempt to put on a legal outer garment for the national separatist forces. Such as the rampant "Pan Turkic theory" on the declared: Hungarians in European history is the Huns in Chinese history, they are the Turkic peoples of the earliest ancestors. Chinese scholar Liu Yan-gang pointed out in his book "The History of Huns" (2016) that many evidences and recent studies by academics can prove that it is impossible for Hungarians to originate from the Huns. The story of using the Huns to prove that the Han dynasty far surpassed that of Rome did not really. As for the relationship between the Huns and Turks, it is even not worth mentioning.

\subsection{To Protect the Silk Road Intangible Cultural Heritage, Prosperity of All Ethnic Groups Silk \\ Road Culture, Improve the Cultural Quality of All Ethnic Groups.}

Due to the harsh natural environment and the continuous struggle, especially the vandalism of non-Islamic culture after the Islamization, the material and cultural aspects of the Silk Road have almost disappeared. Although the material culture is irreversible, the relevant institutional culture and spiritual culture have been deeply rooted in the inner world of all ethnic groups in Silk Road. For example, during the activities of worshiping Mazar listed in Volume 39 of the Western Regions Charter, some traditions of worship of fire, Shamanism and even Buddhism were preserved. Islam prohibits idolatry, but Uyghurs have the image of "Seven and Zhuo," and chant "worship" to idols. 
During the pilgrimage in Mazar, accompanied by a dance of shamanic dancing in the rough, danced branches around Mazar, tied up the branches of trees and shrubs, and hung the hide, head and tail of sacrificial livestock on the wooden pole together, Offer sacrifices to the dead and so on. Therefore, Silk Road ethnic culture by no means a single Islamic culture, but the integration of East and West cultures, with a brilliant history. At the same time, the non-material culture of Silk Road peoples is also very prosperous. Taking Uyghur medical documents as an example, its content is very extensive and covers the ancient Uighur medical theory and practice. Specifically, its contents include various diseases and their symptoms, diagnosis and treatment, medicine deployment and preservation.

4.4 Provide Humane Tourism Resources, Increase and Broaden the Local Income Channels Along the Silk Road, and Raise the Economic Level in Ethnic Areas.

Gobi, deserts, snow-capped mountains, grasslands, and many peaks and peaks in the eastern section of Silk Road form a natural tourism resource, which provides resources for tourism activities. But to see that if only the natural beauty, people will soon produce aesthetic fatigue. Therefore, it is necessary to increase the resources of humanistic tourism on the basis of the tourism of natural scenery so as to attract a steady stream of foreign tourists. Humanistic tourism resources, also known as cultural tourism resources, refer to cultural landscapes formed by various social environments, people's lives, historical relics, culture and arts, ethnic customs and material production. As humanities have their own traditional characteristics, they become the objects of tourists' sightseeing. They are the crystallization of human history and culture and are the concentrated reflection of the national style. They not only contain the spiritual and material wealth left over from the long history of mankind, but also include all aspects of today's human society. The research on non-Chinese documents of Silk Road is conducive to humanistic tourism, and then through various forms such as folk performances, style experiences, and so on, to improve tourism revenue and residents' income of local governments in the eastern section of Silk Road.

\subsection{To Enhance National Image, Enhance Pride and Confidence, Develop Patriotic Enthusiasm and International Vision.}

Since the emergence of the Islamic Sahifist jihadists in the 1980s, the eastern Silk Road has been constantly invaded by Islamic extremists. In particular, Xinjiang suffered. The constant violence and terrorist activities have given rise to certain prejudices against ethnic minorities who believe in Islam, especially the Uyghurs. At the same time, this has also caused the Uyghurs to suffer some shame and crack down on national self-confidence. The study of non-Chinese literatures in the eastern section of Silk Road will make Uyghurs realize that Islamic Salafism is not the mainstream ideology of Uyghurs, and that the socialist outlook on social harmony is the core Uyghur worldview.

\subsection{Provide Reference Materials for the Rational Formulation and Effective Implementation of \\ Ethnic Policies and Religious Policies to Combat the Erosion of Illegal Religions and Extreme Religious Beliefs.}

The formulation of ethnic and religious policies must not only consider the status quo but also consider history. Neglecting history and reality can only have unfortunate consequences, based on emotions alone. Taking the development of Islam in Xinjiang as an example, after the 1980s, because individual cadres only considered the needs of religious believers and built mosques vigorously, the number reached more than 20,000. This strong religious atmosphere has caused some people who are not religiously religious to have to give in, especially in the areas of eastern and northern Xinjiang. In fact, we can see from the literature that the Uighur beliefs were varied in the past. They include not only Shamanism but also Manichaeism, Nestorians, and Taoist religions. Buddhism in particular, continued until the Mongolian period (even in the Hami area until the 16th century). It can be said that the Uyghur people in some areas do not completely believe in Islam. In addition, Uighur traditional culture is an oasis agricultural culture, Islamic culture is only part of its culture, that is, religious culture. However, when conducting research or writing books, some scholars often equate Uyghur culture with Islamic culture and equate social customs with religious rituals, which objectively hurts most of the secular masses. Therefore, based on the historical and cultural characteristics of the ethnic minorities in Xinjiang, formulating national policies and religious policies according to local 
conditions and seeking truth from facts can maximize the fight against ideology and resist the erosion of illegal religions and extreme religious beliefs.

\section{Conclusion}

To sum up, China has the innate advantages and long history of studying silk non-Chinese literature, it is bound to shine for the continuation of this research. The top priority is to break the regional barriers and give the power of the whole nation to carry out the research. It is necessary to have the top-level design from the social sciences management departments as well as the front lines of social science research. In our opinion, guided by the theory of historical linguistics and through a combination of studies on the history of languages, it will certainly promote the research on the non-Chinese literatures of Silk Road to a new stage.

\section{References}

[1]. Chen Yanqi and Sasha. (1990) Bibliography of The Western Regions Research. Urumqi: Xinjiang People's Press.

[2]. Wang Su. (2010) A Study on the Literature of Dunhuang and Turpan. Beijing: Cultural Relics Press.

[3]. Gansu Association of Social Sciences. (1989) Catalogue of The Silk Road Literature. Lanzhou: Lanzhou University Press.

[4]. Wu Fengpei. (1993) The Supplement of The Silk Road Reference. Beijing: Zhong Hua Book Company.

[5]. Miao Pusheng. (2006) Chinese Northwest Literature Collection Beijing: Thread-Binding Books Publishing House. 